\title{
OLEOGRANULOMA \\ THE LATE EFFECTS OF ACCIDENTAL INJECTION OF MINERAL OIL UNDER PRESSURE
}

BY

\section{B. MOORE}

\section{From the Public Health Laboratory, Exeter}

Accidental introduction into the tissues of mineral oil under pressure is an occupational hazard which has come into some prominence in recent years. The picture presented by victims of this accident in the early stages has been stressed in all the published reports. The aim of this paper is to draw attention to the disastrous late effects that may follow such an accident. These have been predicted by a number of writers, largely by analogy with certain comparable conditions; but I have not been able to find records of any late cases in the literature.

The characteristic early manifestation of this type of accident is the grease-gun injury to the hand (see Brooke and Rooke 1939, Smith 1939, Byrne 1944). This is associated with the accidental injection into the subcutaneous tissues of the fingers of lubricating grease delivered under high pressure from the nozzle of the grease-gun now commonly used in garages. A similar type of injury has been reported in Diesel engine operators (see Rees 1937, Dial 1938, de Lacerda Filho 1941, Hughes 1941). Mason and Queen (1941) described an intermediate stage following grease-gun injuries, in which nodular tumours developed at the site of injection of the mineral oil and persisted with apparently little change for considerable periods. They showed that histologically the tumours were essentially the result of an intense productive fibrosis around a nidus of mineral oil in the tissues. The term 'oleogranuloma' more aptly reflects, therefore, the pathological process involved, and is used here in preference to the term 'oleoma' used by the above authors and other writers.

Mason and Queen stressed the importance of adequate surgical removal of the mineral oil from the tissues, predicting that serious late results would otherwise follow. This view was based on the work of Hesse which will be mentioned below; but it is supported by a number of parallels in the literature, which may be briefly summarized:-

1. In 1899 it was suggested that paraffin of high melting point should be used as a means of correcting disfigurements of the face or other parts of the body. The results at first appeared satisfactory, but it was later found that in a relatively small proportion of cases the end-results were disastrous owing to the formation of hard subcutaneous nodules which developed at the sites of injection and spread into the surrounding tissues. Chronic ulceration and scarring followed, and the only satisfactory treatment of the affected tissues was complete excision followed by skin grafting.

2. During the Great War of 1914-1918, the injection of mineral oil into the lower limbs was practised in White Russia as a way of evading military service. The rationale of this was that the oil was known to produce a factitious tumour, and according to an old Russian law any man unable to wear the regulation high field boot was exempt from military service. Hesse, of Leningrad, described 183 such cases in 1925 . The majority of these presented with bony-hard tumours, usually around the knee joint; some had, in addition, overlying ulceration and scarring. Eleven years later, in 1936, Hesse's assistant, Vinogradov, published a paper describing some late results in Hesse's cases, and this paper is the only one in the literature which gives a complete natural history of oleogranuloma from the early stages to the development of late sequelae. In advanced cases, the nodular tumours caused lymphatic obstruction and elephantiasis; multiple ulcers developed following trivial injuries and healed slowly with abundant scar tissue, and the final stages showed chronic deep ulceration occasionally with malignant change. A proximal spread of the tumour masses, sometimes with lymphnode enlargement, was also noted, and was correctly attributed to spread of the foreign oil particles along lymph channels. Amputation was the only satisfactory treatment.

3. Oleogranuloma of the upper limbs was described in the years following the influenza pandemic of 1918 as a result of multiple.injections of camphorated oil, the vehicle being liquid paraffin. A typical case was that described by Mook and Wander (1919), which showed the same 'concretelike' infiltration, the elephantiasis, and the proximal spread of nodules along lymphatic channels which the Russian authors later described.

4. Another considerable group comprises the oil strictures of the rectum, due to injections of phenol in oil in the treatment of haemorrhoids. Rosser published a series of 26 cases in 1931, with symptoms ranging from rectal neuralgia to complete obstruction, and proved experimentally that the mineral oil and not the phenol was responsible (see also Jackman 1940).

. 5. Finally, one may mention lipoid pneumonia, 
the adult type of which is due usually to long-continued instillation of mineral oil sprays into the upper respiratory tract. Clinically these cases simulate pulmonary neoplasm, and the histological picture is essentially the same as is seen in the other oleogranulomas (see Ikeda 1937). There is, therefore, abundant evidence of the disastrous late results which follow the injection of mineral oil into the tissues; and it is clear that the only way to avoid these late sequelae is adequate surgical removal of the irritant oil as early as possible.

\section{Case Report}

The following case report is a distressing commentary on the need for radical treatment of such cases at an early stage:-

Case History. Male, aged 47. Occupation: Engineer's erector. A well-built man with no previous medical history. Six years ago, while working on high scaffolding, he slipped and fell about six feet on to a pipe containing a heavy lubricating oil under pressure. The end of this pipe penetrated a few inches through the right side of his scrotum and into his perineum, and then snapped across, so that an unknown volume of oil was injected under pressure into his ischio-rectal tissues. He extracted the broken pipe, and being anxious to finish the task on which he was engaged, continued with his work. The wound healed within a few weeks without any treatment.

Nine months later, i.e. about five years ago, he was admitted to a hospital in Derbyshire with a large acute perineal abscess, which was drained. He spent four months as an inpatient in this hospital before his wound healed.

Two and a half years ago, in October 1943, he was first admitted to the Radcliffe Infirmary, Oxf rd, under Mr. Whitelocke. He presented as a cellulitis, with temperature $100^{\circ} \mathrm{F}$, pulse 80 ; and showed a large, hard, painful swelling which extended forward from the perineal region to the front of the right pubic ramus, with an extension into the right side of his scrotum. He was treated with sulphonamides, and the swelling subsided after three weeks. During this time he had acute retention of urine for a few days. This responded rapidly to treatment with an indwelling catheter, but since then he has lost the normal stimulus to micturition, his first indication of vesical distension now being hypogastric pain.

When his acute cellulitis subsided, it was found that he had a hard mass extending upwards along the righ side of the rectum as far as a finger could reach, and hard

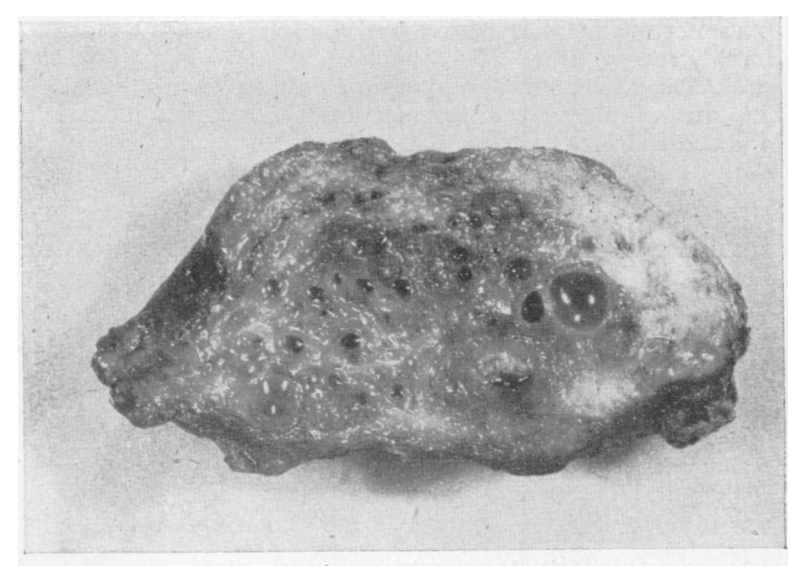

FIG. 1.-Section of scrotal nodule showing oil-containing cavities in a dense mass of fibrous tissue. Approximately natural size. nodules in the skin of the perineum, one in the scrotum and one in the anterior rectus sheath. Biopsy was performed on the ischio-rectal tissues, and the histological diagnosis of oleogranuloma was made. The biopsy wound healed very slowly and a scrotal abscess developed two months after the operation and was incised. Cultures yielded Staph. aureus and $\beta$-haemolytic streptococci. Further outpatient treatment lasting five months preceded his discharge in May, 1944.

During the following four months he had increasing pain and tenderness in the scrotal nodule, which was gradually becoming larger. He also began to suffer from severe hypogastric pain, especially at night.

In August, 1944, he was readmitted to the Radcliffe Infirmary and the scrotal nodule was excised. Six weeks later he was sent to a convalescent home with his operation wound still unhealed. Here his abdominal pain became more severe and on October 22 nd he was readmitted to the Radcliffe Infirmary as a possible acute abdominal emergency, with extremely severe hypogastric pain radiating into both loins. This pain gradually responded to morphine, and he returned to the convalescent home. In December, 1944, he was discharged to his home in the North Midlands at his own request. Follow-up inquiries supplement the history as follows:-

16.5.45. Admitted to his local hospital for incision of an ischio-rectal abscess. He was discharged a week later with his wound still draining.

14.6.45. Readmitted with orchitis and scrotal cellulitis. He was treated with sulphonamides. Ten days later a discharge of pus from his scrotum started, and this continued for four weeks. He was finally discharged on 7.8.45.

7.9.45. In a personal letter, the patient said he was still suffering from abdominal pain and that his scrotal wound was not yet healed.

21.3.46. Patient still unable to resume work and complaining of a hard scrotal swelling and a discharging wound in his right groin.

Finally, it may be mentioned that the engineering firm by which the patient was employed has refused responsibility for compensation on the grounds that at the time of the accident the patient was working single-handed. This contravened one of their regulations which directed that no employee should work on a scaffolding without having an assistant to help him.

The macroscopic and microscopical appearances of the two specimens from this patient are very similar, and correspond very closely to the findings in other types of oleogranuloma. Fig. 1 is a photograph of the scrotal nodule which was excised in September, 1944. This nodule measured $4 \times 4 \times 2 \mathrm{~cm}$. and was firm in

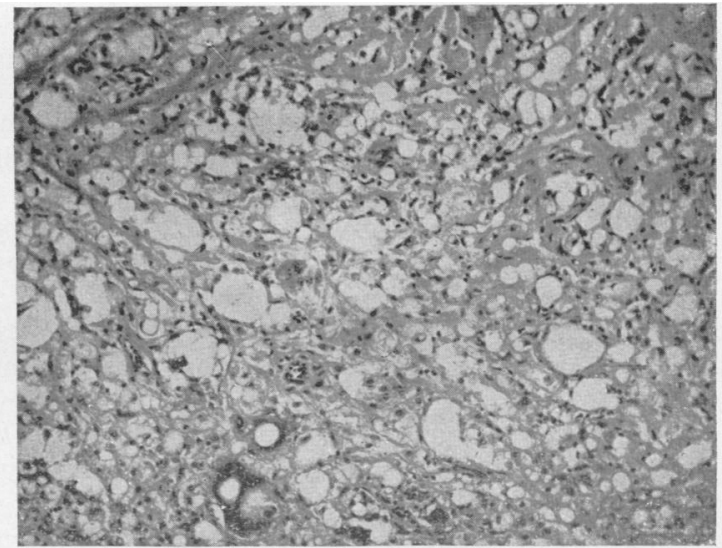

FIG. 2.-Granulomatous tissue with empty spaces representing encysted oil $(\times 110)$. 


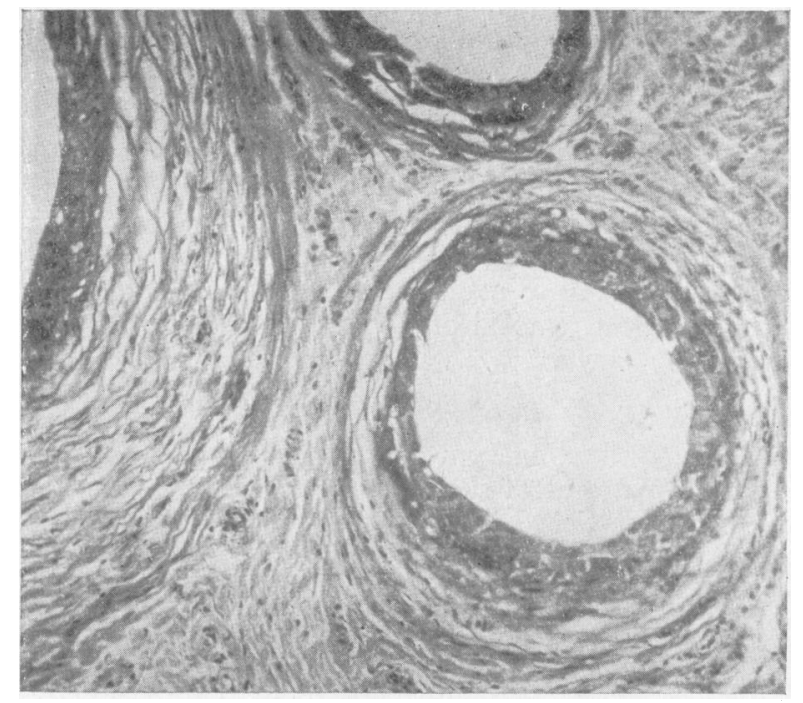

FIG. 3.-Larger space with layer of flattened histiocytes inside the fibrous tissue capsule $(\times 110)$.

consistency. The cut surface was yellow and greyishyellow in colour and was studded with numerous cavities containing an amber-coloured oily fluid.

Microscopically, one sees what is essentially a marked foreign-body reaction with a characteristic picture of active granulation tissue enclosing the foreign oil in cysts of very varying sizes, which are represented by empty spaces in ordinary H. \& E. preparations (fig. 2). The larger spaces are ringed by a fairly dense fibrous tissue capsule, inside which is a layer of flattened histiocytes (fig. 3). The latter, in sections stained with Sudan, are seen to contain fat globules. There are numerous histiocytes scattered through the fibrous tissue of the nodule, and a few polymorphonuclear leucocytes, and occasional foreign-body giant cells. Sections stained for fat show large numbers of globules staining orangered with Sudan and occupying the large and small spaces seen in paraffin sections. Under the fluorescence microscope, the globules, examined in unstained frozen sections, show a vivid blue fluorescence.

\section{Discussion}

The course of the chronic illness manifested by this patient is very similar to that followed by Hesse's cases. Owing to the site of the lesion the mechanical results of lymphatic obstruction are not evident, but the recurrent infections are an index of the devascularization and diminished resistance caused by the intense productive fibrosis occurring in this disease. It is possible that the severe abdominal pains are associated with upward spread of the granulomatous process along lymphatic channels, as was seen in Hesse's patients.

The progressive course of oleogranuloma suggests that the pathological process is more than a simple foreign-body reaction on the part of the tissues to the presence of an inert foreign substance. One might postulate some chemical irritant effect comparable to that which plays an important part in the pathogenesis of silicosis. There is, in fact, some evidence that this may be the case. Workers handling the heavy fraction obtained on distillation of crude oils are subject to severe skin reactions ranging from the results of mechanical blockage of sweat-ducts and hair-follicles to a definite epithelial proliferation in the form of warts which occasionally becóme malignant. These lesions are probably due to impurities which for technical reasons are difficult to remove; they do not occur in workers who handle purified solid paraffins. Another fact which supports the idea of a chemical irritant effect is the relatively low incidence of oleogranuloma in cases where paraffin was used for plastic repair. If the response to the injection of paraffin were a simple foreign-body reaction, one would have expected the development of oleogranuloma and its effects in at least the majority of such cases. Some writers have attempted to explain the matter on a basis of allergy, but it seems more probable that certain batches of paraffin contain impurities which stimulate excessive fibrosis in patients into whom they are injected.

\section{Summary}

1. Previous reports concerning the late effects of parenterally introduced mineral oil on the tissues are briefly reviewed.

2. The clinical and pathological findings in a late case of oleogranuloma of the perineum, caused by accidental injection of lubricating oil, are described.

\section{Acknowledgement}

My thanks are due to Dr. A. H. T. Robb-Smith for his interest in this paper, and for advice on its presentation.

\section{REFERENCES}

Brooke, R., and Rooke, C. J. (1939). Brit. med. J., 2, 1186.

Byrne, J. J. (1944). J. Amer. med. Ass., 125, 405

Dial, D. E. (1938). Ibid., 110, 1747.

Hesse, E. (1925). Arch. f. klin. Chir., 136, 277.

Hughes, J. E. (1941). J. Amer. med.'Ass., 116, 2848.

Ikeda, K. (1937). Arch. Path., 23, 470.

Jackman, R. J. (1940). Proc. Mayo Clinic, 15, 188.

de Lacerda Filho, N. (1941). Bahia Med., 12, 63.

Mason, M. L., and Queen, F. B. (1941). Quart. bull. N. W. Univ. med. School, Chicago, 15, 122.

Mook, W. H., and Wander, W. G. (1919). J. Amer. med. Ass., 73, 1340 .

Rees, C. E. (1937). Ibid., 109, 866.

Rosser, C. (1931). Ibid.,'96, 1762.

Smith, F. W. (1939). Abid., 112, 907. $99,2167$.

Vinogradov, D. (1936). Arch. f. klin. Chir., 187, 69. 